\title{
Kliniğimizde yapılan vaskülarize serbest doku nakillerinin irdelenmesi
}

\author{
Examination of vascularized free tissue transfers performed in our clinic
}

Ramazan Hakan Özcan, Başak Karasu

\begin{abstract}
Özet
Amaç: Serbest flep; Doku defekti çevresinden onarımın mümkün olmadığı durumlarda, vasküler pedikülü ile birlikte dokuların alıcı bölgedeki damarlara anastomozu ile transfer edilmesidir. Kliniğimizde serbest flep transferi yapılan hastalar retrospektif olarak incelenmiştir. Hastalar, cinsiyet, yaş, ilk tanıları, rekonstrüksiyon alanı, onarımda kullanılan serbest flep, hastanede kalış süresi, komplikasyonlar ve takip sonuçları açısından değerlendirilmiştir.

Gereç ve yöntem: Çalışmamızda Ocak 2009-Ocak 2020 tarihleri arasında 117 hastaya 123 serbest flep ile rekonstrüksiyon yapılmıştır. 25 flep baş boyun bölgesine, 8 flep üst ekstremiteye, 59 flep alt ekstremiteye, 3 flep genital bölgeye ve 22 flep memeye transfer edilmiştir. Latissimus dorsi (31), serratus anterior (19) ve transvers rectus abdominis (18) en sık kullanılan fleplerdir. 7 hastada osteomiyelit mevcut olup enfekte kemik debridmanı sonrası serbest flep ile onarım yapılmıştır. Meme rekonstrüksiyonu için en uygun seçenek derin inferior epigastrik arter bazlı abdominal serbest fleplerdir.

Bulgular: En erken taburculuk postop 6. günde olup transvers rectus abdominis serbest flebi ile meme rekonstrüksiyonu yapılan hastaya aittir. En sık karşılaşılan komplikasyon flep kenarlarında parsiyel detaşman ve nekroz olup 11 hastada izlenmiştir. Yalnızca 2 hastada dolaşım bozukluğu sebebiyle total flep nekrozu görülmüştür.

Sonuç: Genel başarı oranımız flep yaşayabilirliği açısından uluslararası literatür ile uyumlu olup \% 97,5 olarak bulunmuştur. Kozmetik ve fonksiyonel başarılı sonuçlar, donör bölge morbiditesinin azlığı nedeniyle pediküllü fleplerin ikinci seçenek olması sonucuna ulaştırmıştır.
\end{abstract}

Anahtar kelimeler: Serbest flep, mikrocerrahi, doku defekti, rekonstrüksiyon.

Özcan RH, Karasu B. Kliniğimizde yapılan vaskülarize serbest doku nakillerinin irdelenmesi. Pam Tıp Derg 2020;13:385-391.

\begin{abstract}
Purpose: Free flap; is the transfer of the tissue with its vascular pedicle to the vessels in the recipient area by anastomosis, when the tissue defect cannot be repaired with its surrounding tissues. Patients who underwent free flap transfer in our clinic were analyzed retrospectively. Patients were evaluated in terms of gender, age, initial diagnosis, reconstruction area, free flap used in repair, hospitalization time, complications and follow-up results.

Materials and methods: In our study 117 patients were reconstructed with 123 free flaps between January 2009 and January 2020. 25 flaps were transferred to the head and neck region, 8 flaps to the upper extremity, 59 flaps to the lower extremity, 3 flaps to the genital area and 22 flaps to the breast. Latissimus dorsi (31), serratus anterior (19) and transverse rectus abdominis (18) are the most commonly used flaps. Osteomyelitis was present in 7 patients and repair was done with free flap after infected bone debridement. The most suitable option for breast reconstruction is deep inferior epigastric artery based abdominal free flaps.

Results: The earliest discharge is on the 6th postoperative day and it belongs to the patient who underwent breast reconstruction with TRAM free flap. The most common complication was partial detachment and necrosis at the flap margins, and was observed in 11 patients. Only 2 patients had total flap necrosis due to circulatory disorders. In terms of flap viability.

Conclusion: Our overall success rate was found to be $97.5 \%$ in accordance with the international literatüre. Cosmetic and functional successful results have led us to conclude that pedicle flaps are the second choice due to the low donor region morbidity.
\end{abstract}

Key words: Free flap, microsurgery, tissue defect, reconstruction.

Özcan RH, Karasu B. Examination of vascularized free tissue transfers performed in our clinic. Pam Med J 2020;13:385-391.

Ramazan Hakan Özcan, Dr. Öğr. Üye. Pamukkale Üniversitesi Tıp Fakültesi Plastik, Rekonstrüktif ve Estetik Cerrahi Anabilim Dalı, Denizli, Türkiye, e-posta: rhozcan@yahoo.com (orcid.org/0000-0002-4159-8948) (Sorumlu Yazar)

Başak Karasu, Arş. Gör. Pamukkale Üniversitesi Tıp Fakültesi Plastik, Rekonstrüktif ve Estetik Cerrahi Anabilim Dalı, Denizli, Türkiye, e-posta: bas.ka@hotmail.com, (orcid.org/0000-0002-4932-3068) 


\section{Giriş}

Serbest flep; üzerinde deri bulunduran veya bulundurmayan, yumuşak doku, kas, kemik içeren veya bunların bileşimlerinden oluşan dokulardır. Vücuttaki uzak bir yerden vasküler pedikülü ile birlikte aktarılır ve alıcı sahada uygun boyuttaki vasküler yapılara anastomoz ile kan dolaşımı tekrar sağlanır. Bu süreç mikrocerrahi becerileri ve uygun ekipman gerektirir.

Travma veya tümörlerin cerrahi eksizyonu sonrası oluşan defektler, fonksiyonel ve kozmetik açıdan en iyi sonucu veren yöntemler ile onarılmalıdır. Rekonstrüksiyon basamaklarında yer alan greft, lokal flep, uzak flep ve serbest flepler arasındaki seçim mikrocerrahi uygulamaları öncesi en basitten en zora doğru sıralanırken, günümüzde fonksiyonel ve estetik açıdan en iyi sonucun alınacağı teknik ilk sırayı almıştır. Rekonstrüktif plastik cerrahi dahilinde büyük kusurları düzeltebilmek için birçok teknik geliştirilmiştir. Bu teknikler vücudun çeşitli kısımlarındaki doku kusurlarını ya da fonksiyonu düzeltmek amacıyla deri, fasya, kas veya kemik gibi dokuları kullanmayı gerektirir.

Donör alanda oluşturulan morbiditenin en aza indirilmesi, onarım yönteminin seçimini etkileyen bir başka faktördür. Defekte yakın bölgelerden kaldırılan pediküllü fleplerde az veya çok morbidite oluşurken, serbest flep seçeneği bu olasılığı kabul edilebilir düzeylere indirir.

Dünyadaki ilk başarılı serbest flep, 1973 yılında Daniel ve Taylor tarafından gerçekleştirilen free groin fleptir [1]. 1989'da Koshima ve Soeda'nın ilk tanıtımından bu yana, perforatör flepler kısa sürede yumuşak doku rekonstrüksiyonlarında kullanılmaları nedeniyle popülerlik kazanmışlardır [2]. 0,3-0,8 mm'den küçük damarlar için mikro-nörovasküler diseksiyon ve anastomoz sağlayan mikrocerrahi ve süper mikrocerrahi gelişimi ile perforatör fleplerinin uygulamaları yaygınlaşmıştır [3].

\section{Gereç ve yöntem}

Ocak 2009 ile Şubat 2020 tarihleri arasında Pamukkale Üniversitesi Tıp Fakültesi Hastanesi Plastik Rekonstrüktif ve Estetik Cerrahi Kliniği'nde, serbest flep kullanılarak cerrahi rekonstrüksiyon yapılan 117 hasta çalışmaya dahil edildi. Çalışma için Pamukkale
Üniversitesi Tıp Fakültesi Girişimsel Olmayan Klinik Araştırmalar Etik Kurulu'ndan onay alındı. Bu çalışmada vasküler anastomozlar 4,5x loupe (Keeler) ve mikroskop (Leica M525 F50) ile yapıldı. Serbest flep diseksiyonu için $3,0 x$ loupe kullanıldı. Kliniğimizde, karaciğer transplantasyon vakalarına dahil olunarak yapılan hepatik arter anastomozları çalışma dışı bırakıldı.

Toplanan veriler; hastaların cinsiyetleri, yaşları, rekonstrüksiyon alanı, onarımda kullanılan serbest flep, hastanede kalış süresi, komplikasyonlar (serbest flep başarısızlığı veya enfeksiyon, hematom oluşumu ve vasküler tromboz nedeniyle anastomoz tekrarı...vb) ve sonuçlar olarak ayrı ayrı değerlendirildi.

\section{Bulgular}

Serbest flep kullanılan 123 cerrahi girişim tespit edildi ve gözden geçirildi (toplam 117 hasta olup 6 hastada iki serbest flep rekonstrüksiyonu vardır).

Bu dönemde 41 kadın ve 76 erkek hastaya mikrocerrahi serbest doku aktarımı yapıldı. Erkek hasta sayısının yaklaşık iki kat fazla olmasının iş ve motorlu araç kazalarına daha fazla maruz kalmalarının sonucu oluştuğu tespitine varıldı.

Serbest flep yapılan en küçük hastanın yaşı 3 olup erkektir. Kadınlarda en küçük yaş 8 ve en büyük yaş 81 iken erkeklerde en küçük yaş 3 ve en büyük yaş 85 'tir. Kadın yaş ortalaması 45,63 ve erkek yaş ortalaması 45,42 'dir. Tüm hastaların toplam yaş ortalaması ise 45,49 olarak bulunmuştur. Hastaların yaşları cinsiyete göre dekatlar şeklinde ayrılarak gruplandırılmıştır. Şekil 1, hastaların cinsiyete göre yaş dağılımını göstermektedir.

Yeniden yapılandırılan alanlar; baş ve boyun 25 (\%21,36); üst ekstremite $8(\% 6,83)$, alt ekstremite $59(\% 50,42)$, genital bölge $3(\% 2,56)$ ve meme $22(\% 18,8)$ vaka olarak bölümlere ayrılmış olup Şekil 2'de gösterilmiştir.

Baş ve boyun defektleri, trafik kazaları, makinaya kaptırma şeklinde iş kazaları, karsinomlar, sarkomlar, ateşli silah yaralanmaları, mukormikozis, yanık ve radyoterapi sonrası trakeostomi nekrozuna bağı doku defektlerini içermekteydi. 


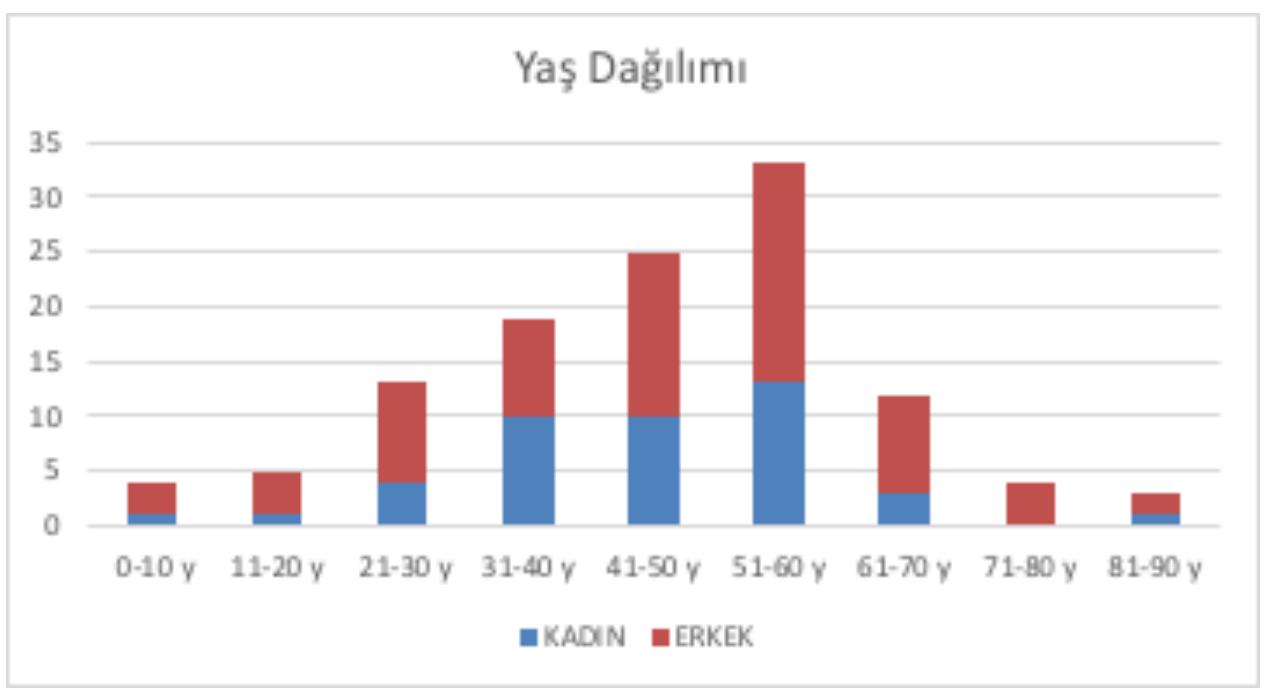

Şekil 1. Hastaların cinsiyete göre yaş dağılımlarının karşılaştırılması.

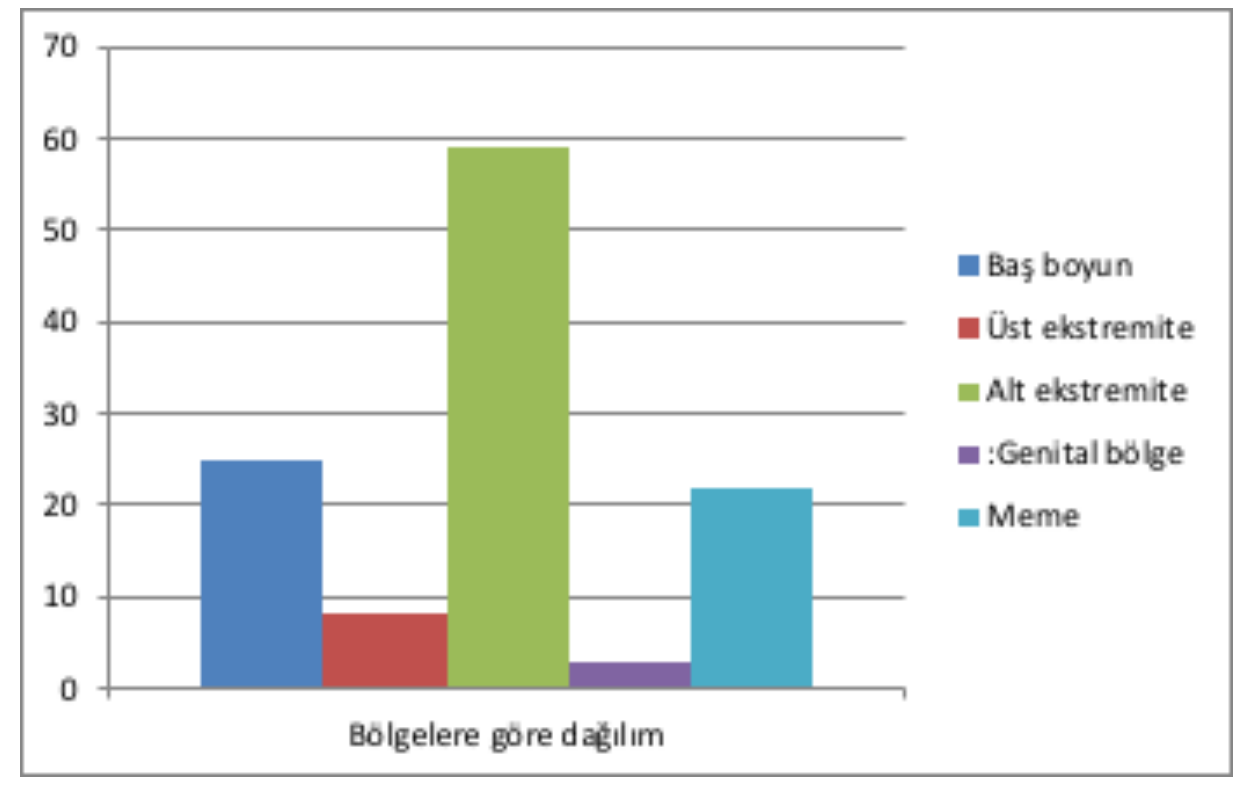

Şekil 2. Serbest flep ile rekonstrüksiyon uygulanan bölgeler.

Üst ekstremite rekonstrüksiyonları, trafik kazaları, makinaya kaptırma şeklinde iş kazaları, karsinomlar, sarkomlar, ateşli silah yaralanmaları ve şiddetli yanık kontraktürüne bağlı doku defektlerini içermekte iken, alt ekstremite rekonstrüksiyonları trafik kazaları, makinaya kaptırma şeklinde iş kazaları, karsinomlar, sarkomlar, ateşli silah yaralanmaları, yanık, fraktür ve plak ekspozisyonu, osteomiyelit, kraş yaralanma ve diyabetik ayak yaralarına bağlı doku defektlerini içermekteydi.

Genital bölge rekonstrüksiyonları Fornier gangreni, ateşli silah yaralanması sonucu penis amputasyonu ve yaygın verrü, nekroza bağlı doku defektlerini içerirken, meme rekonstrüksiyonlarının tamamı meme karsinomuna bağı geçirilmiş mastektomi sonrası meme rekonstrüksiyonlarını içermekteydi.

Kullanılan flepler; latissimus dorsi kas deri free flebi (LD) 31 adet $(\% 25,2)$, serratus anterior kas free flebi (SA)19 adet $(\% 15,5)$, anterolateral uyluk kas deri free flebi (ALT) 16 adet (\%13), radyal ön kol free flebi (RÖK) 9 adet $(\% 7,3)$, transvers rectus abdominis kas deri free flebi (TRAM )18 adet $(\% 14,63)$, derin inferior epigastrik arter perforatör free flebi (DIEP) 7 adet $(\% 5,7)$, fibular kemik kas deri free flebi (FF) 5 adet $(\% 4,07)$, iliak kemik kas free flebi (ILIAK) 5 adet $(\% 4,07)$, lateral femoral sirkumfleks arter free flebi (LFCA) 3 adet $(\% 2,43)$, skapular free 
flep (SF) 3 adet $(\% 2,43)$, lateral torasik arter perforatör free flebi (LTA) 1 adet $(\% 0,8)$, posterior tibial arter preforanı üzerinden fasyokutan free flep (PTAP) 1 adet $(\% 0,8)$ ve diğerleri 5 adet $(\% 4,07)$ olmak üzere toplam 123 adet olarak sınıflandırılmıştır (Şekil 3).

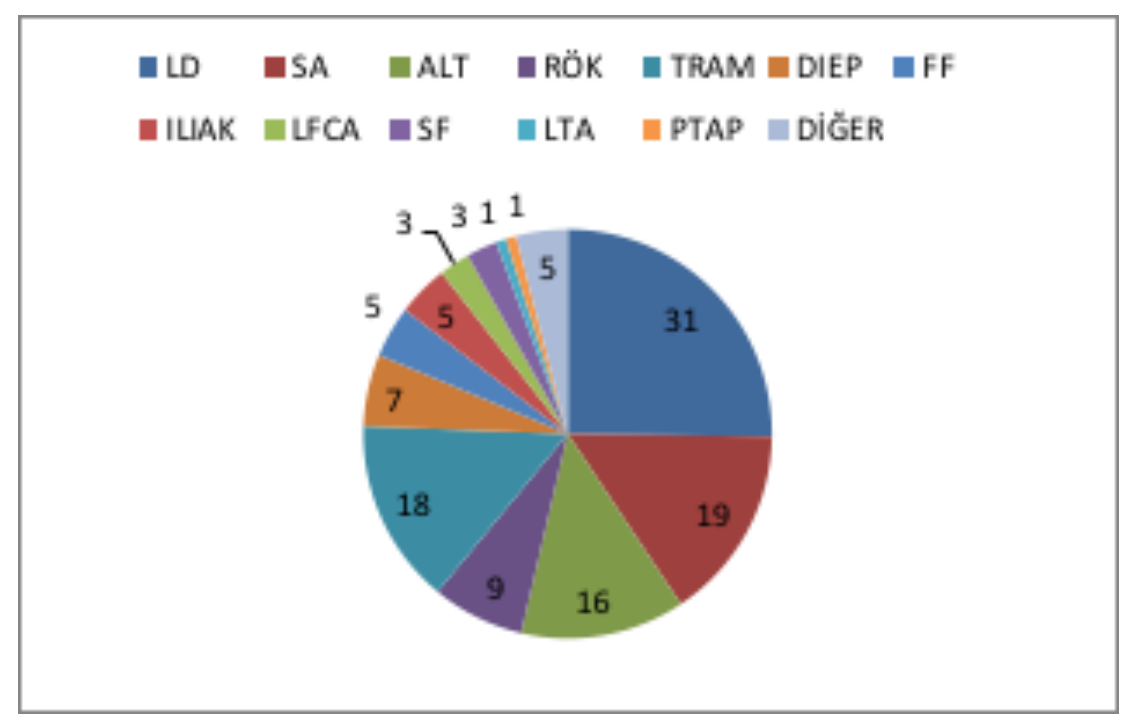

Şekil 3. Kullanılan serbest fleplerin dağılımı.

LD(latissimus dorsi), SA(serratus anterior), ALT(anterolateral uyluk), RÖK(radial ön kol), TRAM(transvers rektus abdominis miyokutanöz), DIEP(derin inferior epigastrik arter perforatör), FF(fibular flep), ILIAK(iliak flep), LFCA(lareral femoral sirkumpleks arter), SF(skapuler flep), LTA(lateral torasik arter), PTAP(posterior tibial arter perforatör)

Hastanede kalış süreleri değerlendirildiğinde; en erken sürede taburcu olan hasta, meme karsinomu sebebiyle modifiye radikal mastektomili olup TRAM free flep operasyonu ardından postop 6. günde taburcu olmuştur. En geç taburcu olan hasta ise Ewing sarkomu sebebiyle maksillektomi yapılan hasta olup genel durum bozukluğu ve ek müdahale gerekliliği sebebiyle tedavi görüp postop 98 . günde taburcu olmuştur. Ortalama hastanede kalış süresi 21 gündür.

En düşük hastanede ortalama kalış süresi 9 gün olup meme rekonstrüksiyonlarına aittir. Baş boyun rekonstrüksiyonlarında ortalama hastanede kalış süresi 23 gün, üst ekstremite rekonstrüksiyonlarında ortalama hastanede kalış süresi 24 gün, alt ekstremite rekonstrüksiyonlarında ortalama hastanede kalış süresi 23 gün ve genital bölge rekonstrüksiyonlarında ortalama hastanede kalış süresi 22 gündür.

İlk yıllarda ameliyat yapılan hastaların hastanede kalış süreleri uzun tutulmuş iken, tecrübe artışına bağlı olarak son senelerdeki olguların hastanede kalış süreleri 6 güne kadar kısalmıştır.

\section{Komplikasyonlar}

Hastalarda operasyon sonrası en çok görülen komplikasyon flep kenarlarında parsiyel nekroz ve detaşman olup 11 vakada izlenmiştir. Debridman ve primer onarım yapılmıştır. 4 vakada geç dönemde tümör nüksü görülmüş olup ek operasyon intiyacı doğmuştur. 5 vakada hematom izlenmiş olup ek operasyon gerektirmemiştir. 4 vakada arteriyel tromboz sebebiyle dolaşım bozukluğu yanısıra 5 vakada ven trombozu izlenmiş olup bu olgularda trombüsler boşaltılıp anastomoz tekrarı uygulanmıştır. 3 vakanın 2'sinde operasyon sahasında tümör nüksü sebebiyle rejeksiyon ve 2 vakada dolaşım bozukluğu sebebiyle total flep nekrozu görülmüştür. 2 vakada alıcı sahada apse meydana gelmiş olup drenaj ve antibiyoterapi uygulanmıştır. Geç dönemde 3 vakaya yapışıklıklar ve asimetri sebebiyle revizyon yapılmıştır. 1 vaka ek hastalıklar varlığı nedeniyle ekstübasyon sonrası solunum arresti sebebiyle yoğun bakıma alınmış olup kardiyak arrest sebebiyle ve diğer 1 vaka da tümör nüksü sebebiyle postoperatif üçüncü ayda ölmüştür. 


\section{Tartışma}

Rekonstrüktif mikrocerrahi, plastik cerrahinin temel bir bileşeni olmaya devam etmekte olup serbest flepler karmaşık kusurların rekonstrüksiyonunda neredeyse her cerrahi tedavi için gelişmiş ve güvenilir seçenek olmaya devam etmektedir. Günümüzde mikrovasküler serbest doku aktarımı büyük doku defekti bulunan vakalarda, açık kemik fraktürlerinde ve osteomiyelitte daha çok tercih edilmektedir.

Bizim çalışmamız, Denizli ve çevre illerden merkezimize gelen serbest flep ile rekonstrüksiyon yapılan hastalarda yüksek başarı ve kurtarma oranlarına sahip olduğunu ve sonuçların uluslararası literatürle karşıllaştırılabilir olduğunu göstermiştir.

Mathes ve ark.'nın $[4,5]$ çalışmaları yanısıra yapılan birçok çalışmada [6-11] enfekte olmuş dokuların debridmanından sonra kas doku içeren fleplerin daha iyi onarım sağladığı belirtilmiştir. Bizim çalışmamızda 7 adet osteomiyelit vakasında enfekte kemik debridmanından sonra, dolaşımlarının daha zengin olmasından ötürü kas dokusu içeren serbest fleplerle rekonstrüksiyon yapılmıştır. Boeckx ve ark.'nın [12] yapmış olduğu çalışmaya benzer şekilde onarım için serratus anterior ve latissimus dorsi içeren free flepler tercih edilmiştir. Resim 1'de sol tibia osteomiyelitli hastanın SA kas flebi + deri grefti ile onarılmış sonucu izlenmektedir.

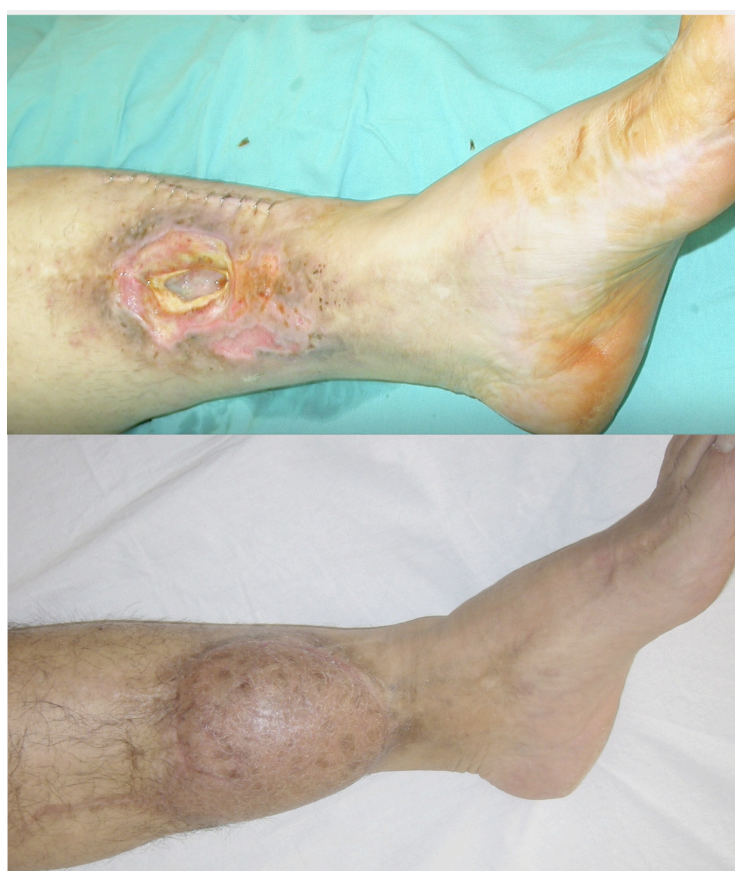

Resim 1. Sol tibia osteomiyelitli hastanın SA kas flebi + deri grefti ile onarılmış sonucu.
Baş boyun defektleri yanısıra penil rekonstrüksiyonlarda ön kolun distal kısmında cildin ince, esnek ve nispeten tüysüz olması sebebiyle radiyal önkol serbest flebi tercih edilmiştir. Bu flep aynı zamanda uzun pedikülü ile intraoral rekonstrüksiyon için boyun damarlarına mikrovasküler anastomozda kolaylık sağlamaktadır. Bizim çalışmamızda olduğu gibi geniş mandibula rezeksiyonu yapılan baş boyun tümörlü hastaların onarımında ise serbest vaskülarize fibula ve iliak kemik flepleri en sık tercih edilen ve önerilen yöntemdir [13]. Resim 2'de intraoral skuamoz hücreli kanser olgusunun serbest radial önkol flebi ile onarılmış sonucu görülmektedir.

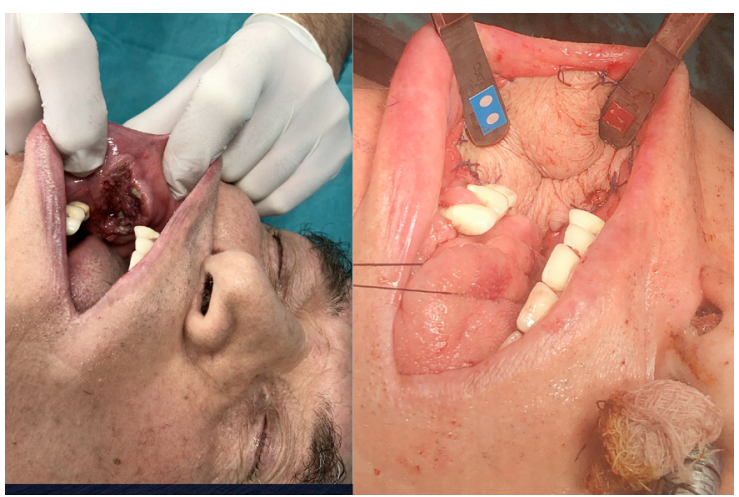

Resim 2. intraoral skuamoz hücreli kanser olgusunun serbest radial önkol flebi ile onarılmış erken sonucu.

Meme rekonstrüksiyonu için en uygun seçenek abdominal bölgeden kaldırılan derin inferior epigastrik arter bazlı fleplerdir. Mikrocerrahi öncesi pediküllü TRAM flep en çok tercih edilirken, günümüzde DIEP ve TRAM serbest flepleri birinci öncelikler olmuştur. Flep yaşayabilirliğinin artması ve donör alan morbiditesinin kabul edilebilir olması önemli avantajlarıdır. TRAM flep ile rekonstrüksiyon uyguladığımız 15 hastanın 10'nunda kas defektinin oluştuğu alana prolen mesh ile fasya onarımı yapılmıştır. Diğer 5 olgu ve DIEP flep yapılan olgularda kas ve fasya parsiyel olarak alındığından fasya defekti primer onarılmıştır [14]. Resim 3'de DIEP flep ile meme rekonstrüksiyonu uygulanan hastanın ameliyat öncesi ve geç postoperatif sonuçları mevcuttur. 


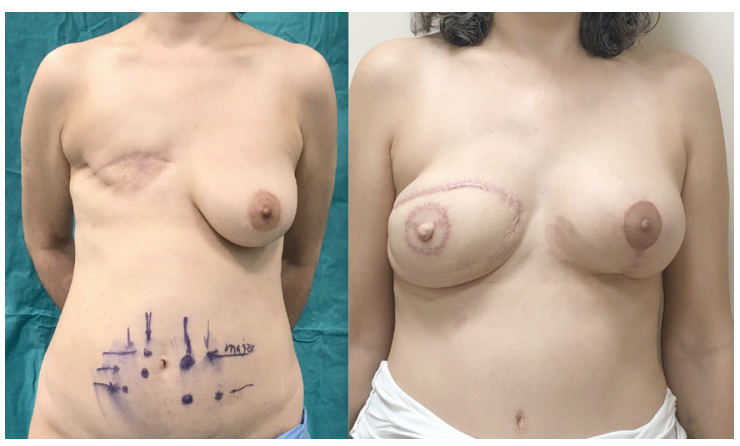

Resim 3. DIEP flep ile meme rekonstrüksiyonu uygulanan hastanın ameliyat öncesi ve geç postoperatif sonuçları.

Flep kayıplarında, anastomoz sahasında tromboz, hiperkoagulasyon, staz ve sigara içimi bilinen en büyük risk faktörleridir [15]. $\mathrm{Bu}$ nedenle tüm serbest doku aktarımlarının ilk 48 saat süresince yakından izlenmesi, gerektiğinde dolaşım bozukluğuna müdahale edilebilmesi açısından kritik öneme sahiptir. Özellikle alt ekstremitedeki posttravmatik vakalar ele alındığında, travmaya bağlı vasküler ve perivasküler doku hasarı da flep kaybına yol açmaktadır. Bizim çalışmamızda total flep kaybı olan vakalar alt ekstremite travmatik yaralanmalarına ve tümör nüksüne bağlı olarak izlenmiştir.

Sonuç olarak, serbest doku transferlerinde başarı oranımızın literatürle benzer olmasında, alıcı damar seçiminde titiz davranımasının katkısı büyüktür. \%97,6 olan flep başarı oranımız Yii ve ark.'nın [16] yapmış olduğu \%99,2, Bui ve ark.'nın [17] yaptığı \%98,8'lik ve Kroll ve ark.'nın [18] yapmış olduğu \%96,8'lik başarı oranına sahip çalışmalarla tutarlıdır. Yerinde endikasyon, titiz mikrocerrahi teknik uygulaması ve özenli ameliyat sonrası takip ile elde edilen başarılı sonuçlar, rekonstrüksiyon seçenekleri içerisinde serbest flepleri ön sıralara çekmiştir.

Çıkar ilişkisi: Yazarlar çıkar ilişkilerinin olmadığını beyan ederler.

\section{Kaynaklar}

1. Daniel RK, Taylor GI. Distant transfer of an island flap by microvascular anastomoses: a clinical technique. Plast Reconstr Surg 1973;52:111-117. https://doi.org/10.1097/00006534-197308000-00001

2. Koshima I, Soeda S. Inferior epigastric artery skin flaps without rectus abdominis muscle. $\mathrm{Br} J$ Plast Surg 1989;42:645-648. https://doi.org/10.1016/00071226(89)90075-1
3. Koshima I, Yamamoto T, Narushima M, Mihara M, lida T. Perforator flaps and supermicrosurgery. Clin Plast Surg 2010;37:683-689. https://doi.org/10.1016/j. cps.2010.06.009

4. Mathes SJ, Feng LJ, Hunt TK. Coverage of the infected wound. Ann Surg 1983;198:420-429.

5. Mathes SJ, Alpert BS, Chang N. Use of the muscle flap in chronic osteomyelitis: experimental and clinical correlation. Plast Reconstr Surg 1982;69:815-829. https://doi. org/10.1097/00006534-198205000-00018

6. Stark WJ. The use of pedicled muscle flaps in the surgical treatment of chronic osteomyelitis resulting from compound fractures. J Bone Joint Surg 1946;28:343-350.

7. Richards RR, Orsini EC, Mahoney JL, Verschuren $R$. The influence of muscle flap coverage on the repair of devascularized tibial cortex: an experimental investigation in the dog. Plast Reconstr Surg 1987;79:946-958.

8. Ger R. Muscle transposition for treatment and prevention of chronic post-traumatic osteomyelitis of the tibia. J Bone Joint Surg 1977;59:784-791.

9. Musharafeh R, Osmani O, Musharafeh U, Saghieh S, Atiyeh B. Effcacy of microsurgical free-tissue transfer in chronic osteomyelitis of the leg and foot: review of 22 cases. J Reconstr Microsurg 1999;15:239-244. https:// doi.org/10.1055/s-2007-1000097

10. Koval KJ, Meadows SE, Rosen H, Silver L, Zuckerman JD. Posttraumatic tibial osteomyelitis: a comparison of three treatment approaches. Orthopedics 1992;15:455460.

11. Arnold PG, Yugueros $P$, Hanssen AD. Muscle flaps in osteomyelitis of the lower extremity: a 20-year account. Plast Reconstr Surg 1999;104:107-110.

12. Boeckx WD, Hulst R, Nanhekhan LV, Lorenzi F. The role of free fleps in the treatment of persistent scalp osteomyelitis. Neurosurgery 2006;59:64-67. https:// doi.org/10.1227/01.NEU.0000219894.58901.46

13. Hidalgo DA. Fibula free flap mandibular reconstruction. Clin Plast Surg 1994;21:25-35

14. Anita T. Mohan AT, Saint Cyr M. Anatomic and physiological fundamentals for autologous breast reconstruction. Gland Surg 2015;4:116-133. https://doi. org/10.3978/j.issn.2227-684X.2015.04.01

15. Zor F, Özturk S, Şahin İ, Işık S. Timing of microsurgical reconstruction of lower extremity: is it really important in flap failure? Turk J Plast Surg 2009;17:105-107. Available at: http://www.turkplastsurg.org/index.php/ tprecd/article/view/1273/271. Accessed Dec 17, 2009

16. Yii NW, Evans GR, Miller M, et al. Thrombolytic therapy: What is its role in free flap salvage? Ann Plast Surg 2001;46:601-604. https://doi.org/10.1097/00000637200106000-00005 
17. Bui DT, Cordeiro PG, Hu QY, Disa JJ, Pusic A, Mehrara BJ. Free flap reexploration: indications, treatment, and outcomes in 1193 free flaps. Plast Reconstr Surg 2007;119:2092-2100. https://doi.org/10.1097/01. prs.0000260598.24376.e1

18. Kroll SS, Schusterman MA, Reece G, et al. Timing of pedicle thrombosis and flap loss after free-tissue transfer. Plast Reconstr Surg 1996;98:1230-1233. https://doi.org/10.1097/00006534-199612000-00017

Etik onayı: Pamukkale Üniversitesi Girişimsel Olmayan Klinik Araştırmalar Etik Kurulu'nun, 28.11.2018 tarih ve 60116787-020/81393 sayılı onayı ile çalışma başlatılmıştır. 